\title{
Numerical modelling techniques for studying longwall geotechnical problems under realistic geological structures
}

\author{
Dung Tien Le*, Tung Manh Bui \\ Hanoi University of Mining and Geology, Hanoi, Vietnam
}

\begin{abstract}
Longwall - associated geotechnical problems have been extensively studied by using numerical modelling methods. However, proper representation of its geological structures remains a challenging task. This paper presents a systematic understanding of numerical modelling techniques for studying longwall coal mining with geological structures. The modelling techniques derived from conventional and advanced continuum and discontinuum methods were reviewed in detail with emphasiz on their mechanic's formulation and applications. This study suggests that the successful selection of a proper modelling technique should be based on the physical principle of longwall problem, texture and shape of materials, and mechanics formulation of the numerical program used for modelling. The paper's conclusions assist numerical modellers in quickly and properly selecting modelling technique for investigating a site - specific longwall problem.
\end{abstract}

Copyright (C) 2021 Hanoi University of Mining and Geology. All rights reserved.

\section{Introduction}

Longwall is one of the most productive underground coal mining methods, and has been widely applied in many coal industries. The method's application has been extended to various geo - mining conditions due to the significant improvement in face equipment (i.e., shield support) and deeper insight into rock mass behaviour around the mined - out area. Longwall geotechnical problems such as entry/roadway

${ }^{*}$ Corresponding author

E - mail: t.d.le@humg.edu.vn

DOI: 10.46326/JMES.2021.62(3).10 stability, face/rib spalling, pillar yielding, roof fall/caving, and floor heave are the objects of many investigations. Depending on the research methods used, those studies shed different lights on the mechanisms driving the problems. For example, according to Galvin (2016), empirical methods (which are based on experiment, field data and observations) may produce an actual response of rock mass around the longwall face. A clear understanding of the underlying physical phenomenon and database for the development is a key for the method's success, as seen in Yu et al. (2015; 2017). Due to the high cost in setting experiment and the long time for implementation at longwall panel, empirical methods should be 
carefully designed before their application. Analytical methods, on the other hand, may reveal fundamental physical principles of longwall behaviours, as can be seen in Wang and Wang (2019) and Le (2021). However, the methods require significant time and effort for solving equations when the problem involves many detailed structures that typically occur in coal measure rocks. On laboratory scale, physical modelling methods can obtain similar results to field experiment at a more reasonable cost, as seen in Sui et al. (2015) and Zhang et al. (2019). The methods still require significant time and effort for constructing models compared to the project time frame.

Compared to the above methods, numerical modelling methods, as based on mathematical equations founded on analytically derived formulae/algorithms (Galvin, 2016), are particularly suitable for studying longwall problems. In particular, the methods can investigate detailed micro - mechanisms of large scale longwall problems within a reasonable time. Compared to physical modelling and analytical methods, numerical methods are more efficient in incorporating many geological structures. Nevertheless, compared to empirical methods, proper modelling of geological structures is more challenging due to the complex geometrical distribution of structures in the field. While the derivation of rock material properties at laboratory scale is reliable through different testing techniques, the derivation at field scale for large - scale modelling such as longwall is limited due to available apparatus and inhomogeneity of geological structures. Although some numerical modelling techniques have been developed for the realistic representation of longwall geological structures, they can be very different in the mechanic's formulation and may be misused if insufficiently understood.

This paper presents a systematic understanding of numerical modelling techniques for studying longwall geotechnical problems under realistic geological structures. Different techniques derived from continuum and discontinuum codes are carefully reviewed. The paper's conclusions and suggestion assist numerical modellers in quickly and properly selecting modelling technique for investigating a site - specific longwall problem.

\section{Continuum modelling techniques}

Finite Difference Methods (FDM) are widely used continuum techniques for studying longwall coal mining. By using the methods, a longwall domain is discretised into many sub - domains whose connectivity between them remains unchanged during the modelling (Kelly et al., 2002). The methods - with representative programs such as FLAC and FLAC3D - have interface elements or slide lines that allow the modelling of discontinuum domain such as longwall coal seam/rock strata to some extent (Itasca Consulting Group, 2019). For example, Bai et al. (2016a) used FLAC2D to study coal wall micro - responses caused by longwall retreat. Although different geometrical configurations of geological structures exist in the stratigraphic column of the area, it seems that the structures are implicitly represented in the model (Figure 1). This representation techniques can also be seen in Li et al. (2018) and Zhang et al. (2019), in which FLAC3D was used to investigate rockburst and roof fracture caused by longwall top coal caving respectively. A longwall panel containing sub horizontal parting planes was explicitly modelled by FLAC3D using interface elements in Behera et al. (2020). The modelling technique did not consider other typical structures such as joints within coal seam (Figure 2). To realistically represent both parting/bedding planes and joints within thick coal seam, Wang et al. (2020) used FLAC3D coupled with a Discrete Fracture Network (DFN) for the modelling (Figure 3). This modelling technique accordingly captured well failure mechanisms caused by longwall mining. However, due to the continuum nature of the program, the technique could not consider realistic caving development in LTCC, which is a key phenomenon to the success of this mining method. Further details on DFN are described in Section 3.2.

\section{Discontinuum modelling techniques}

Distinct Element Methods (DEM) are widely used discontinuum techniques for studying longwall mining. By using the methods, a longwall domain is divided into an assemblage of discrete 


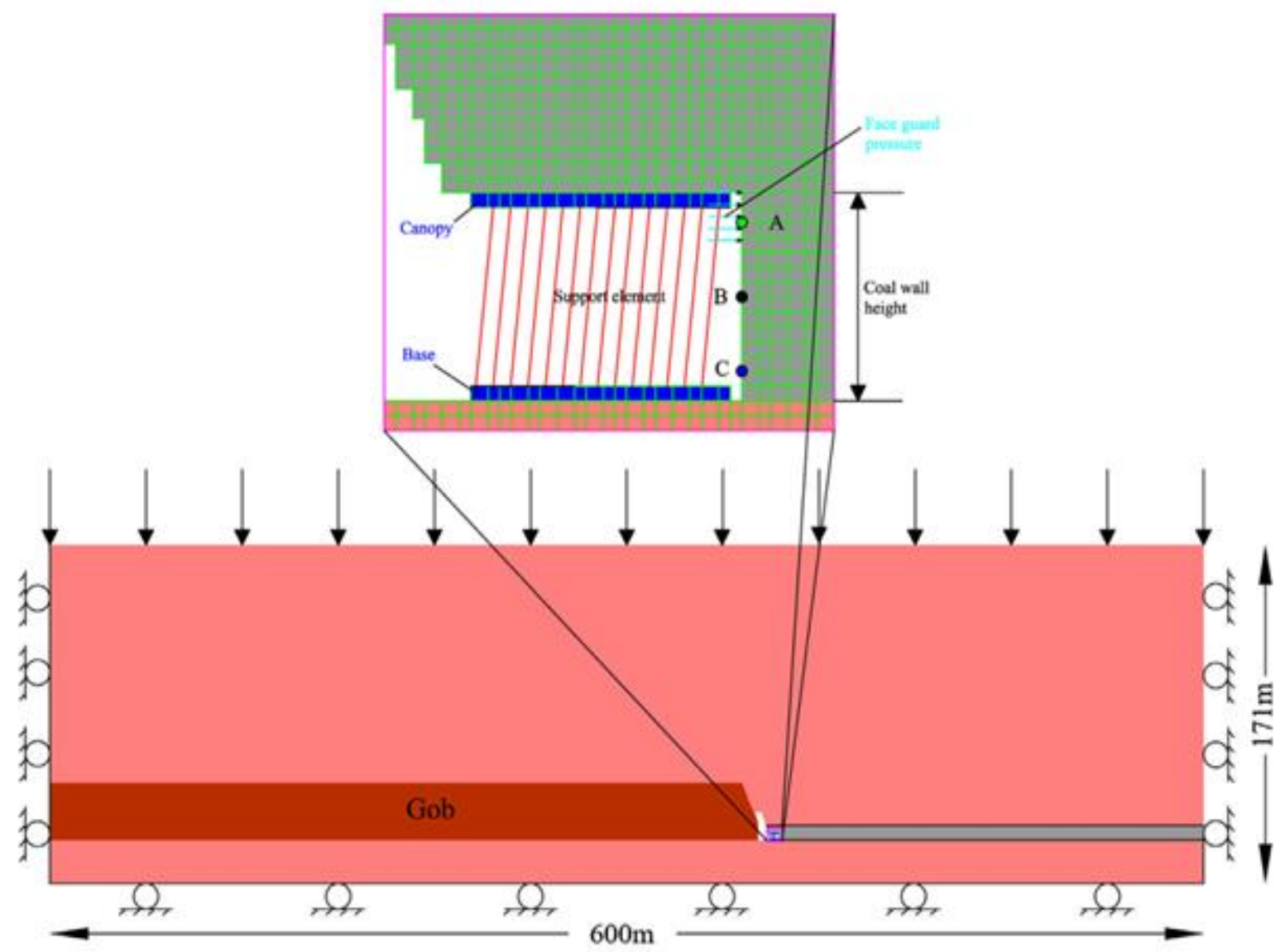

Fiaure 1. FI.AC.2D model of lonawall retreat (Rai et al.. $2016 a$ ).

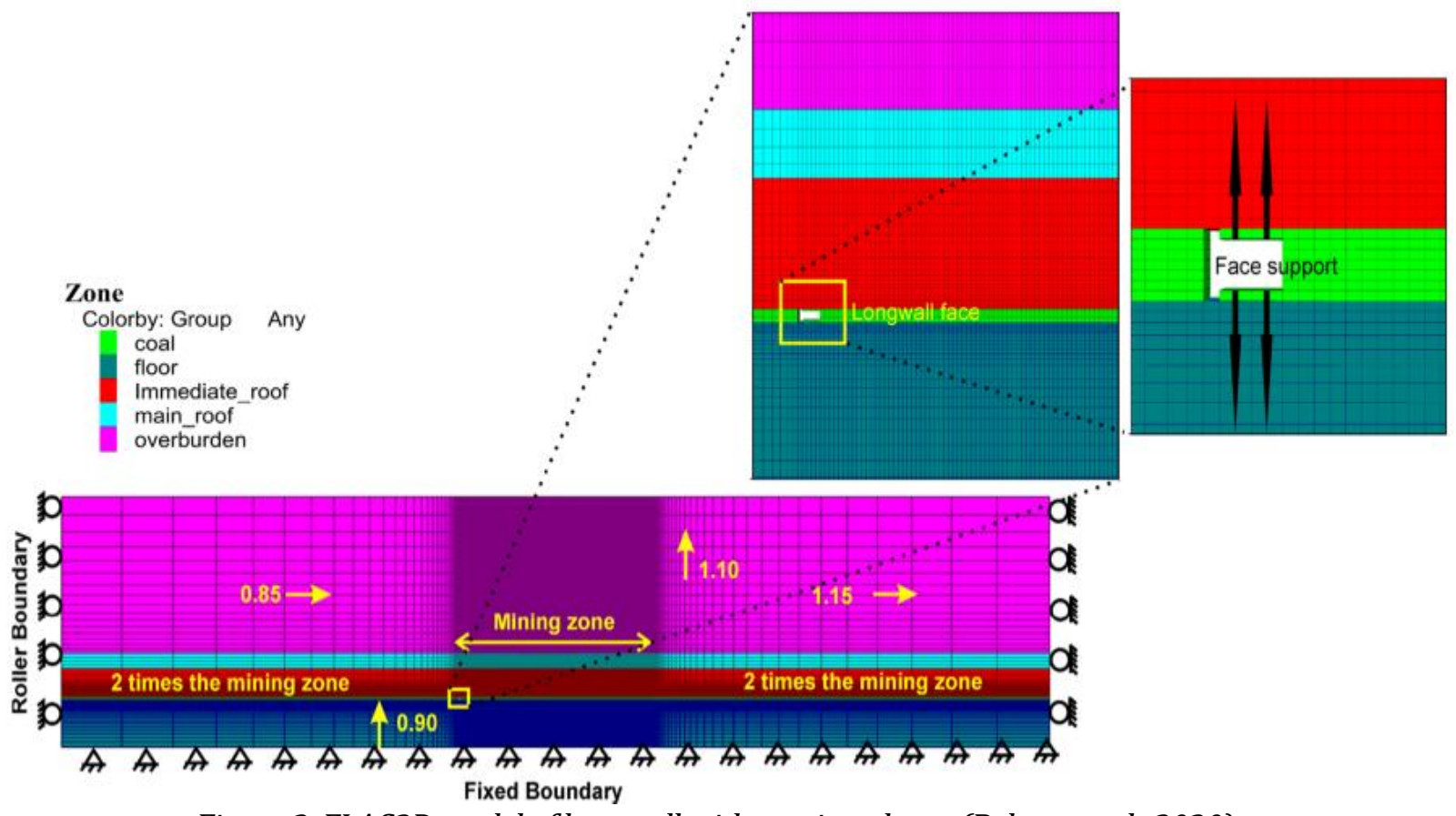

Figure 2. FLAC3D model of longwall with parting planes (Behera et al., 2020). 
(a)
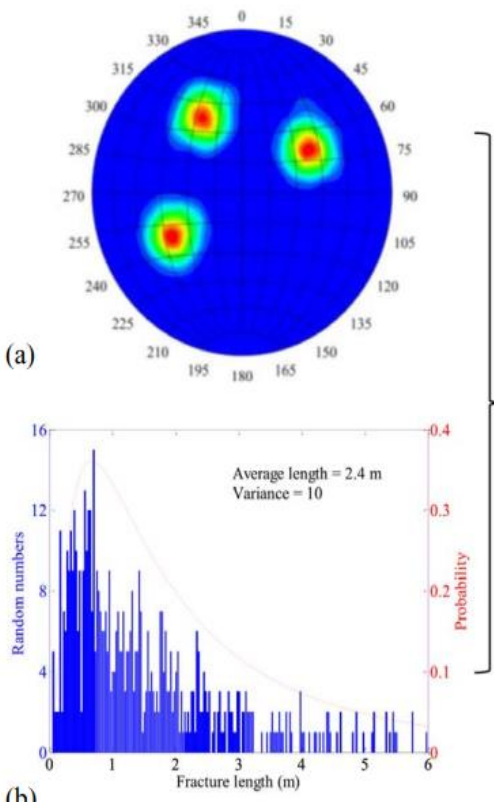

(b)
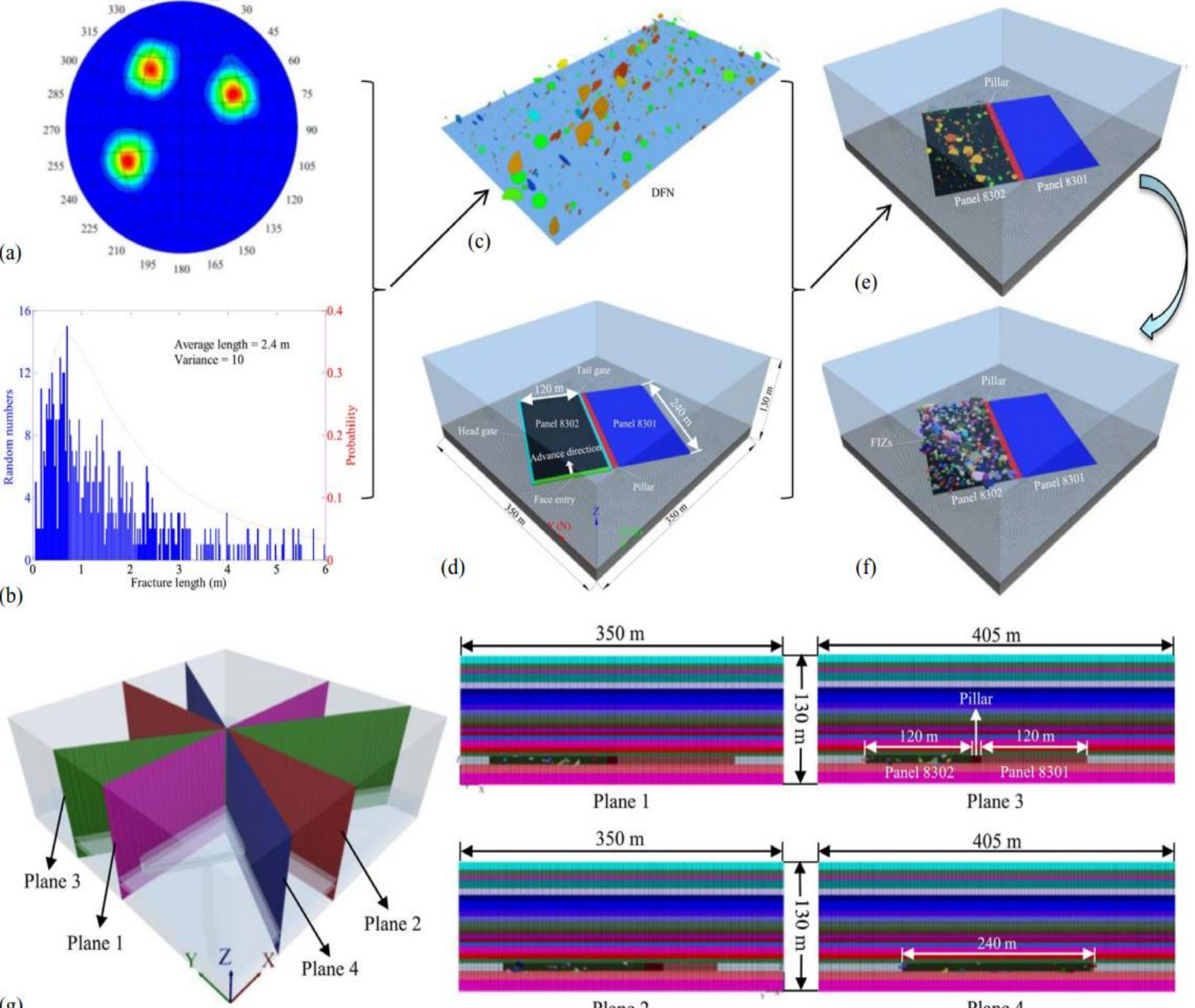

(g)

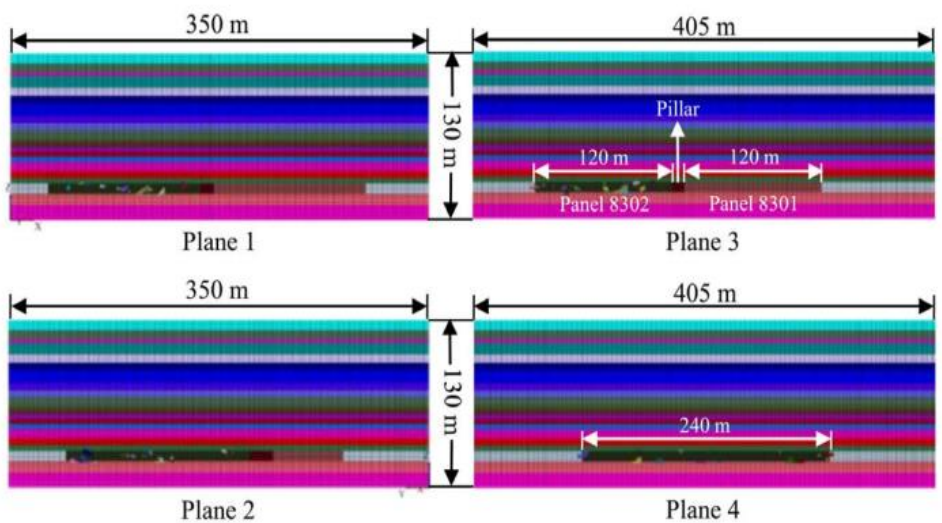

Figure 3. Longwall model with DFN - FDM (Wang et al., 2020).

a) pre - existing fracture orientations; (b) pre - existing fracture lengths; (c) DFN realization; (d) FDM model; (e) FDM - DFN model; (f) fracture influenced zones; and (g) geometrical size of model.

blocks formed by connected fractures (Le et al., 2017). The methods - with representative programs such as UDEC, 3DEC, PFC2D, PFC3D are most suitable for moderately fractured rock mass as in longwall coal mining. The use of DEM in representing geological structures in longwall model can be classified into conventional, Discrete Fracture Network (DFN), and Grain Based Model (GBM) technique as follows.

\subsection{Conventional technique}

A conventional joint generator built - in DEM based programs (e.g., UDEC) is used to create sets of geological structures in a longwall model. A set of structures are defined by statistical geometrical parameters such as dip angle, trace length, gap length, spacing, and spatial location. This modelling technique has been widely used to study coal caving/spalling under typical structures such as horizontal bedding planes and vertical joints (Wang et al., 2016; Kong et al., 2019; Le and Bui, 2020). Note that in these studies, the structures are persistent throughout the strata. At a smaller longwall - scale problem (i.e., longwall entry), the conventional joint generator was also used to model non - persistent vertical joint sets, which can be considered as DFNs, as seen in Abousleiman et al. (2020) (Figure 4). 


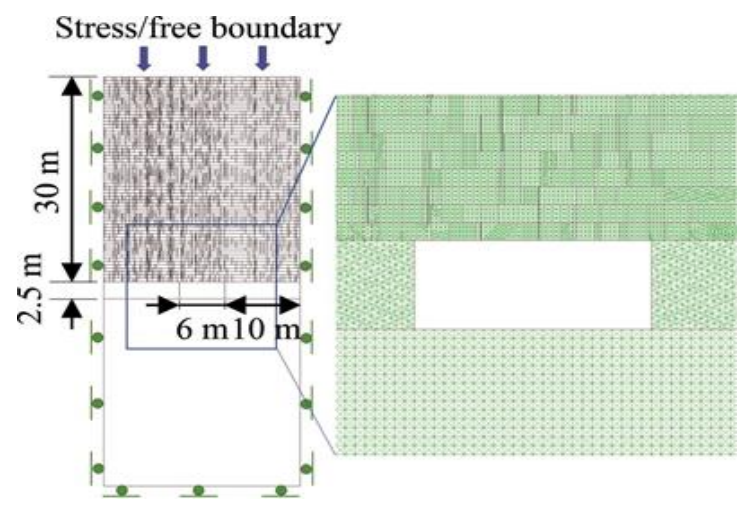

Figure 4. Longwall entry model with DFN (Abousleiman et al., 2020).

\subsection{DFN technique}

The basic concept, generation, advantage, and disadvantage of DFN technique can be found in many papers and textbooks. According to Jing (2003), Elmo and Stead (2010), Mas Ivars et al. (2011), and Hadjigeorgiou (2012), DFN was developed since the 1980s to study fluid flow and transport process within jointed rock masses through a network of connected fractures. A DFN is generated based on the geometry of the fracture system and the persistence of individual fractures. The fracture system geometry is established based on the stochastic distribution of characteristics such as density, orientation, size, aperture, and persistence. One major advantage of this technique is the realistic simulation of fracture distribution at the field. However, because the field measurement of fracture characteristics can only be implemented at limited space (e.g., outcrop, underground exposure, drill core), the reliability of the modelled DFN is highly dependent on the number, availability, and quality of field measurement. Application of DFN in mining and civil geomechanics along with challenges in building conceptual model, collecting field data, and simplifying, calibrating, and validating DFN are described in detail in Lorig et al. (2015).

For stratified rock mass as in underground coal mine, DFN has been used mostly in the "Synthetic Rock Mass - SRM" technique (Pierce et al., 2007) for studying the effect of scale and anisotropy on coal mechanical properties (Deisman et al., 2010; Scholtès et al., 2011; Gao et al., 2014b; Wang et al., 2019a; Wang et al., 2019b; Karimi Sharif et al., 2019). In such studies, the dimension of the SRM is commonly about several meters, which is much less than a typical longwall dimension. The use of DFN in the 3D longwall problem remains, however, very limited. This is because when the problem scale increases, the detail level of the DFN model significantly increases that requires excessive solution time. The detail level may decrease in large - scale 2D longwall problems, as for longwall entry stability (Abousleiman et al., 2020; Zhu et al., 2020) (Figure 5). It should be noted that in the mentioned entry study, the DFN was created by using a built - in conventional joint generator, while in the roof study, a third - party DFN

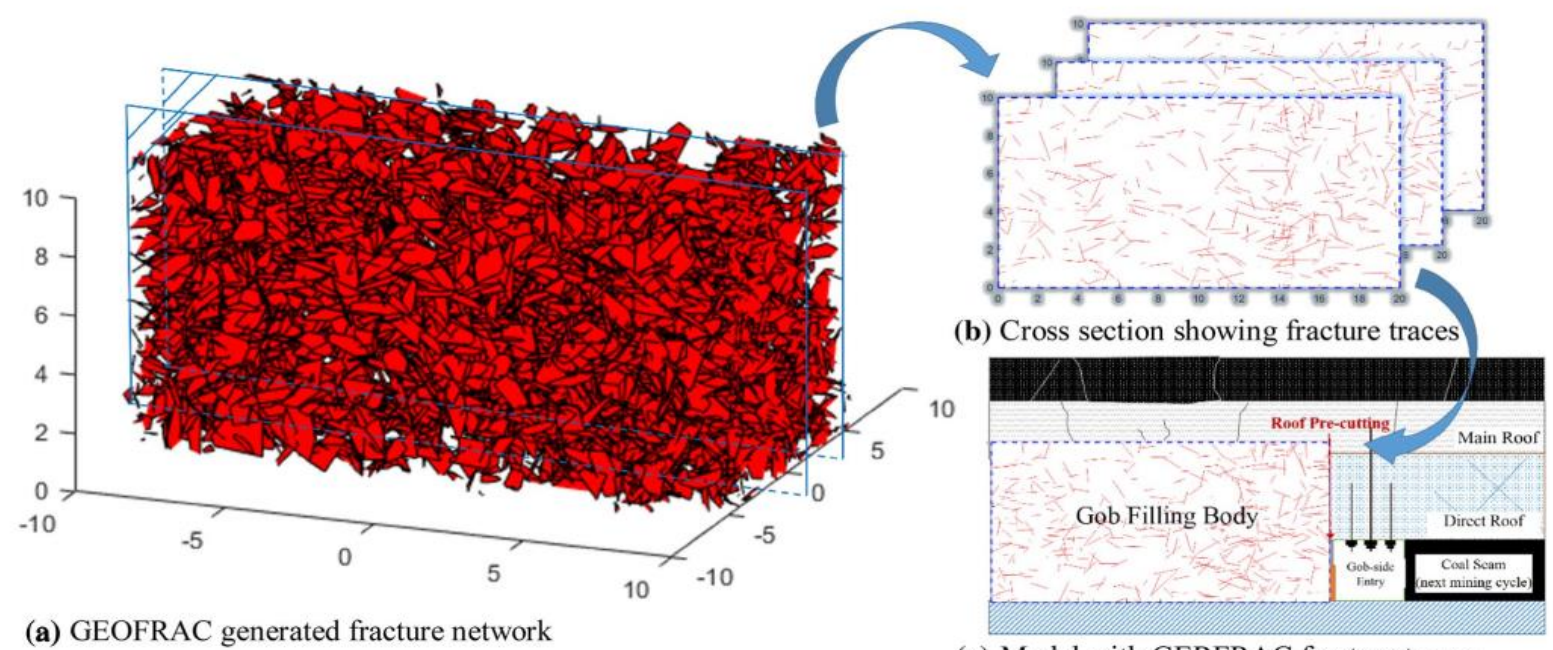

(c) Model with GERFRAC fracture traces

Figure 5. Longwall gob - size entry model with DFN - DEM (Zhu et al., 2020). 
generator named GEOFRAC (Ivanova et al., 2014) was used. Other DFN generators can also be listed, such as FracMan (Golder Associates, 2020) used in Wang et al. (2019b), or MoFrac (https://www.mofrac.com/, 2020) used in Farahmand et al. (2018) and Wang and Cai (2019).

\subsection{GBM technique}

GBM reflects the use of polygonal structures (e.g, grain mesh, Voronoi, and Trigon tessellations) to model grain - shaped material mostly in DEM based numerical programs (Damjanac et al., 2007; Potyondy, 2010; Lan et al., 2010; Gao and Stead, 2014). GBM was first used in UDEC by Lorig and Cundall (1987) to overcome the intrinsic limitation of UDEC that this program cannot explicitly model intact block failure. GBM generation is done by subdividing an intact block into smaller polygonal blocks through Voronoi logic or triangular blocks through Trigon logic in arbitrary sizes (Itasca Consulting Group, 2019). The contacts (or boundaries) between polygons are not representative of natural fractures but play potential paths for failure development in the rock mass. The micromechanical properties of contacts and polygons must be calibrated to match the modelled rock mass's behavior against reality. The calibration process can be simple by, for example, adjusting contact strength (Lorig and
Cundall, 1987; Trueman et al., 1996) or contact stiffness (Nicksiar, 2013). Since 2010, a few standard calibration processes were established for the derivation of a unique set of contact micro - properties for matching on - site rock mass response (Kazerani and Zhao, 2010; Kazerani, 2013; Gao and Stead, 2014). Due to the standard process in calibration and advantage in modelling failure development, GBM has been widely used in UDEC for studying longwall stability such as roadway (Coggan et al., 2012; Gao et al., 2014c; Bai et al., 2016b), roof strata (Gao et al., 2014a; Li et al., 2016), surface subsidence (Zhang et al., 2017), coal face (Yao et al., 2017), and coal pillar (Wu et al., 2019) (Figures 6 - 7). The use of GBM, however, must take into consideration the disadvantages and uncertainties of the technique. For example, according to Gao and Stead (2014), micro - properties of contacts created by Voronoi logic seem to be overestimated after calibration and the solution time increases significantly. Mayer and Stead (2017) and Zhang and Wong (2018) emphasise that Voronoi logic reduces kinematic freedom of polygonal blocks that facilitates tensile failure. Meanwhile, Trigon logic increases the kinematic freedom of triangular blocks that facilitates shear failure. The two GBM logics may misrepresent realistic failure mechanisms if they do not sufficiently represent the texture and shape of minerals constituting rock mass.

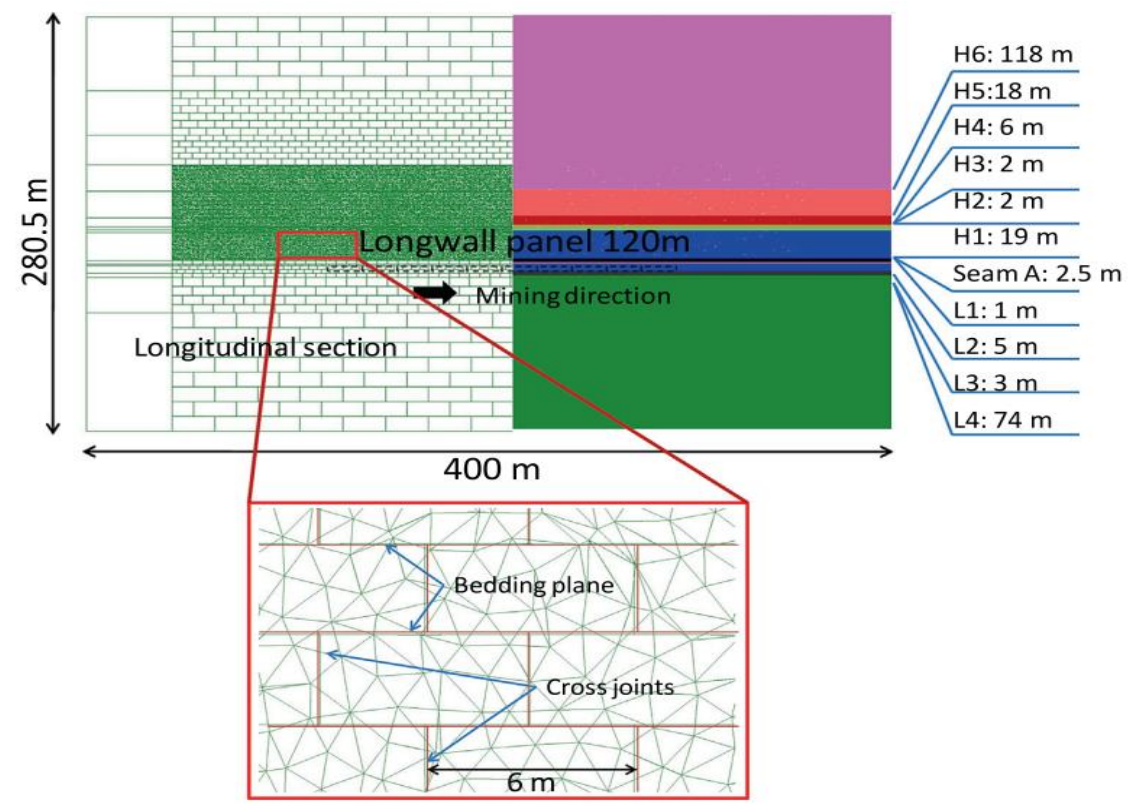

Figure 6. Longwall roof stability model with Trigon logic (Gao et al., 2014a). 


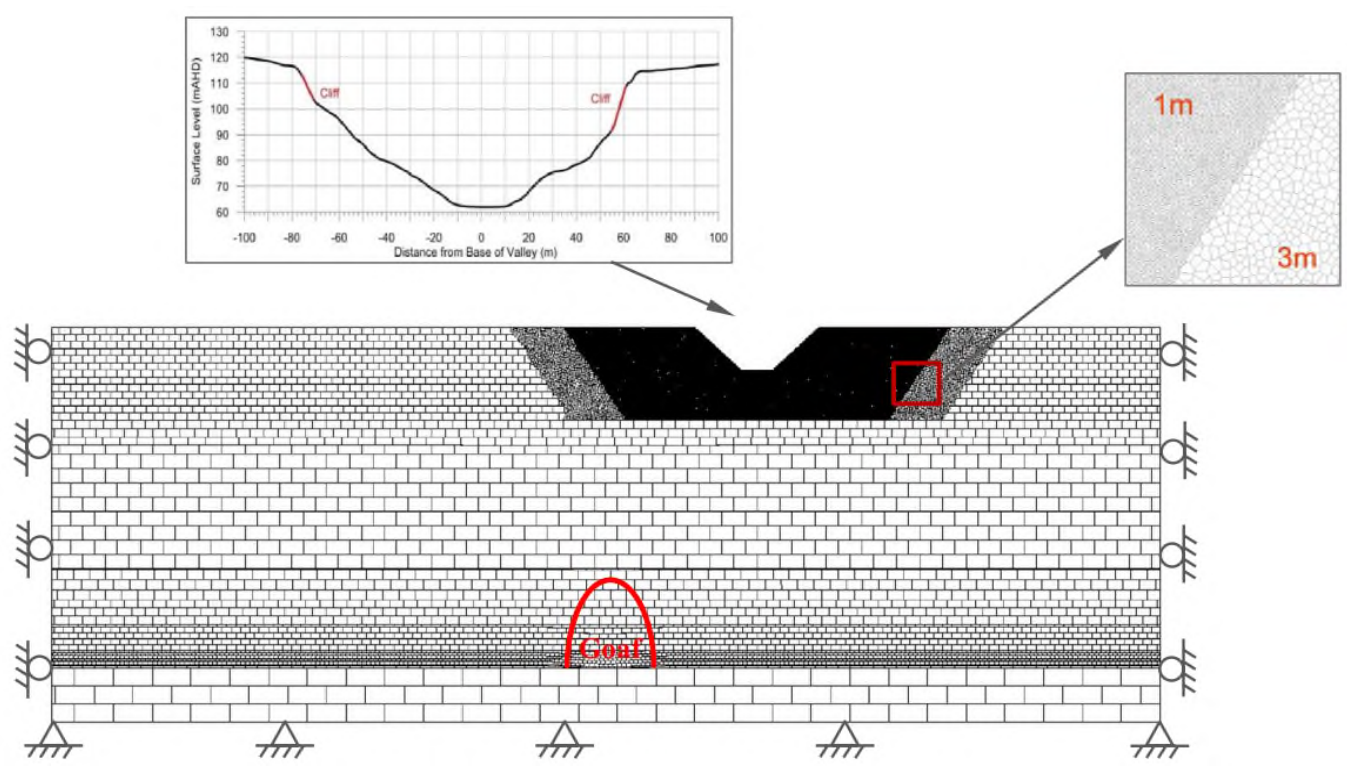

Figure 7. Longwall surface subsidence model with Voronoi logic (Zhang et al., 2017).

\section{Conclusions}

This paper presents a systematic understanding of numerical modelling techniques for studying longwall geotechnical problems under realistic geological structures. The modelling techniques derived from conventional and advanced continuum and discontinuum methods were reviewed in detail with emphasis on their mechanics formulation and applications. For FDM - based techniques, the current study confirms that they well represent the micro mechanics of rock mass failure rather than explicit caving caused by unjointed or moderately bedded coal seam/roof strata in longwall. The continuum formulation of the programs, on the one hand, limits the complete and large detachment of elements in the domain. On the other hand, it may break down the calculation process when many discontinuities (e.g., geological structures) are incorporated. For DEM - based techniques, the study finds a wide use from longwall entry stability to coal wall spalling, roof caving, and roof fracture. Conventional joint generator built in the programs is found to be limited to modelling deterministic fractures which are persistent. DFN logics are seen to be suited for explicit representation of stochastic fractures as in practice, but their use in longwall problems is currently limited and mainly in 2D.
Note that due to the 3D nature of geological structure distribution, the 2D modelling must be implemented with care for retaining the representativeness of the problem's structure. At the same time, GBM logics are suited for the representation of explicit failure and caving development along well - calibrated fictitious fractures. This study suggests that the successful selection of a proper modelling technique should be based on the physical principles of longwall problems, textures and shapes of materials constituting problems, and mechanics formulation of the numerical program used for modelling.

\section{Author contributions}

Dung Tien Le reviewed and wrote the introduction and discussion; Tung Manh Bui collected documents and wrote the conclusions.

\section{Acknowledgements}

This research is funded by Hanoi University of Mining and Geology, Vietnam.

\section{References}

Abousleiman, R., Walton, G. \& Sinha, S. (2020). Understanding roof deformation mechanics and parametric sensitivities of coal mine entries using the discrete element method. 
International Journal of Mining Science and Technology, 30, 123 - 129.

Bai, Q. - S., Tu, S. - H., Chen, M. \& Zhang, C. (2016a). Numerical modeling of coal wall spall in a longwall face. International Journal of Rock Mechanics and Mining Sciences, 88, 242 - 253.

Bai, Q. - S., Tu, S. - H., Zhang, C. \& Zhu, D. (2016b). Discrete element modeling of progressive failure in a wide coal roadway from water rich roofs. International Journal of Coal Geology, 167, 215 - 229.

Behera, B., Yadav, A., Singh, G. S. P. \& Sharma, S. K. (2020). Numerical Modeling Study of the Geo mechanical Response of Strata in Longwall Operations with Particular Reference to Indian Geo - mining Conditions. Rock Mechanics and Rock Engineering, 53, 1827 - 1856.

Coggan, J., Gao, F., Stead, D. \& Elmo, D. (2012). Numerical modelling of the effects of weak immediate roof lithology on coal mine roadway stability. International Journal of Coal Geology, 90-91, 100 - 109.

Damjanac, B., Board, M., Lin, M., Kicker, D. \& Leem, J. (2007). Mechanical degradation of emplacement drifts at Yucca Mountain - A modeling case study: Part II: Lithophysal rock. International Journal of Rock Mechanics and Mining Sciences, 44, 368 - 399.

Deisman, N., Mas Ivars, D., Darcel, C. \& Chalaturnyk, R. J. (2010). Empirical and numerical approaches for geomechanical characterization of coal seam reservoirs. International Journal of Coal Geology, 82, 204 212.

Elmo, D. \& Stead, D. (2010). An Integrated Numerical Modelling-Discrete Fracture Network Approach Applied to the Characterisation of Rock Mass Strength of Naturally Fractured Pillars. Rock Mechanics and Rock Engineering, 43, 3 - 19.

Farahmand, K., Vazaios, I., Diederichs, M. S. \& Vlachopoulos, N. (2018). Investigating the scale - dependency of the geometrical and mechanical properties of a moderately jointed rock using a synthetic rock mass (SRM) approach. Computers and Geotechnics, 95, 162 $-179$.
Galvin, J. M. (2016). Ground engineering Principles and practices for underground coal mining, Cham, Springer International Publishing.

Gao, F., Stead, D. \& Coggan, J. 2014a. Evaluation of coal longwall caving characteristics using an innovative UDEC Trigon approach. Computers and Geotechnics, 55, 448 - 460.

Gao, F., Stead, D. \& Kang, H. (2014b). Numerical investigation of the scale effect and anisotropy in the strength and deformability of coal. International Journal of Coal Geology, 136, 25 37.

Gao, F., Stead, D. \& Kang, H. (2014c). Simulation of roof shear failure in coal mine roadways using an innovative UDEC Trigon approach. Computers and Geotechnics, 61, 33 - 41.

Gao, F. Q. \& Stead, D. (2014.) The application of a modified Voronoi logic to brittle fracture modelling at the laboratory and field scale. International Journal of Rock Mechanics and Mining Sciences, 68, 1 - 14.

Golder Associates (2020). FracMan. Seattle: Washington.

Hadjigeorgiou, J. (20120. Where do the data come from? Transactions of the Institutions of Mining and Metallurgy, Section A: Mining Technology, 121, 236 - 247.

Https://Www.Mofrac.Com/. (2020). MoFrac [Online]. Available: https://www.mofrac.com/ [Accessed 21 June 2020].

Itasca Consulting Group (2019). UDEC - Universal Distinct Element Code, Ver. 7.0. Minneapolis: Itasca.

Ivanova, V. M., Sousa, R., Murrihy, B. \& Einstein, H. H. (2014). Mathematical algorithm development and parametric studies with the GEOFRAC three - dimensional stochastic model of natural rock fracture systems. Computers \& Geosciences, 67, 100 - 109.

Jing, L. (2003). A review of techniques, advances and outstanding issues in numerical modelling for rock mechanics and rock engineering. International Journal of Rock Mechanics and Mining Sciences, 40, 283 - 353. 
Karimi Sharif, L., Elmo, D. \& Stead, D. (2019). Improving DFN - geomechanical model integration using a novel automated approach. Computers and Geotechnics, 105, 228 - 248.

Kazerani, T. (2013). A discontinuum - based model to simulate compressive and tensile failure in sedimentary rock. Journal of Rock Mechanics and Geotechnical Engineering, 5, 378 - 388.

Kazerani, T. \& Zhao, J. (2010). Micromechanical parameters in bonded particle method for modelling of brittle material failure. International Journal for Numerical and Analytical Methods in Geomechanics, 34, 1877 1895.

Kelly, M., Luo, X. \& Craig, S. (2002). Integrating tools for longwall geomechanics assessment. International Journal of Rock Mechanics and Mining Sciences, 39, 661 - 676.

Kong, D., Liu, Y. \& Zheng, S. (2019). Sensitivity analysis of influencing factors and control technology for coalface failure. Arabian Journal of Geosciences, 12, 550.

Lan, H., Martin, C. D. \& Hu, B. (2010). Effect of heterogeneity of brittle rock on micromechanical extensile behavior during compression loading. Journal of Geophysical Research, 115, B01202.

Le, T. D. (2021). Analytical Study on the Stability of Longwall Top Coal Caving Face. In: BUI, X. N., LEE, C. \& DREBENSTEDT, C. (eds.) Proceedings of the International Conference on Innovations for Sustainable and Responsible Mining (ISRM 2020). Cham: Springer International Publishing.

Le, T. D. \& Bui, X. N. (2020). Effect of Key Parameters on Top Coal First Caving and Roof First Weighting in Longwall Top Coal Caving: A Case Study. International Journal of Geomechanics, 20, 04020037.

Le, T. D., Mitra, R., Oh, J. \& Hebblewhite, B.( 2017). A review of cavability evaluation in longwall top coal caving. International Journal of Mining Science and Technology, 27, 907 - 915.

Li, X., Ju, M., Yao, Q., Zhou, J. \& Chong, Z. (2016). Numerical Investigation of the Effect of the
Location of Critical Rock Block Fracture on Crack Evolution in a Gob - side Filling Wall. Rock Mechanics and Rock Engineering, 49, 1041 - 1058.

Li, Z. - L., He, X. - Q., Dou, L. - M. \& Song, D. - Z. (2018). Comparison of rockburst occurrence during extraction of thick coal seams using top - coal caving versus slicing mining methods. Canadian Geotechnical Journal, 55, 1433 1450.

Lorig, L. J. \& Cundall, P. A.( 1987) Modeling of reinforced concrete using the distinct element method. In: SHA, S. P. \& SWARTZ, S. E., eds. International Conference on Fracture of Concrete and Rock, Houston, Texas. 276 - 287.

Lorig, L. J., Darcel, C., Damjanac, B., Pierce, M. \& Billaux, D. (2015). Application of discrete fracture networks in mining and civil geomechanics. Mining Technology, 124, 239 254.

Mas Ivars, D., Pierce, M. E., Darcel, C., Reyes Montes, J., Potyondy, D. O., Paul Young, R. \& Cundall, P. A. (2011). The synthetic rock mass approach for jointed rock mass modelling. International Journal of Rock Mechanics and Mining Sciences, 48, 219 - 244.

Mayer, J. M. \& Stead, D. (2017). Exploration into the causes of uncertainty in UDEC Grain Boundary Models. Computers and Geotechnics, 82, $110-123$.

Nicksiar, M. (2013). Effective parameters on crack initiation stress in low porosity rocks. $P h D$ Thesis, University of Alberta.

Pierce, M., Mas Ivars, D., Potyondy, D. \& Cundall, P. A. A Synthetic Rock Mass Model for Jointed Rock. In: EBERHARDT, STEAD \& MORRISON, eds. Rock Mechanics: Meeting Society's Challenges and Demands, 2007. London: Taylor \& Francis Group, 341 - 349.

Potyondy, D. 2010. A grain - based model for rock: Approaching the true microstructure. In: LI, C. C., GRØNENG, G., OLSSON, R. \& ENGEN, S., eds. Rock Mechanics in the Nordic Countries, 2010. Kongsberg, Norway: Norwegian Group for Rock Mechanics, 225-234.

Scholtès, L., Donzé, F. - V. \& Khanal, M. 2011. Scale 
effects on strength of geomaterials, case study: Coal. Journal of the Mechanics and Physics of Solids, 59, 1131 - 1146.

Sui, W., Hang, Y., Ma, L., Wu, Z., Zhou, Y., Long, G. \& Wei, L. 2015. Interactions of overburden failure zones due to multiple - seam mining using longwall caving. Bulletin of Engineering Geology and the Environment, 74, 1019 - 1035.

Trueman, R., Coulthard, M. A. \& Poulsen, B. A. Numerical methods for estimating the stability of unsupported spans for highwall mining. In: AUBERTIN, M., HASSANI, F. \& MITRI, H., eds. 2nd North American Rock Mechanics Symposium, 1996/1/1/ 1996 Montreal. Rotterdam: A. A. Balkema.

Wang, C., Zhang, C., Li, Y. \& Zheng, C. 2019a. Numerical investigation of the mechanical properties of coal masses with $\mathrm{T}$ - junctions cleat networks under uniaxial compression. International Journal of Coal Geology, 202, 128 $-146$.

Wang, J. \& Wang, Z. 2019. Systematic principles of surrounding rock control in longwall mining within thick coal seams. International Journal of Mining Science and Technology, 29, 65 - 71.

Wang, J., Wang, Z. \& Li, Y. 2020. Longwall Top Coal Caving Mechanisms in the Fractured Thick Coal Seam. International Journal of Geomechanics, 20, 06020017.

Wang, J., Yang, S. \& Kong, D. 2016. Failure mechanism and control technology of longwall coalface in large - cutting - height mining method. International Journal of Mining Science and Technology, 26, 111 - 118.

Wang, X. \& Cai, M. (2019). A DFN-DEM Multi scale Modeling Approach for Simulating Tunnel Excavation Response in Jointed Rock Masses. Rock Mechanics and Rock Engineering, 53, 1053-1077.

Wang, X., Kang, H. \& Gao, F. 2019b. Numerical investigation on the shear behavior of jointed coal mass. Computers and Geotechnics, 106, $274-285$.
Wu, W. - D., Bai, J. - B., Wang, X. - Y., Yan, S. \& Wu, S. - X. 2019. Numerical Study of Failure Mechanisms and Control Techniques for a Gob - Side Yield Pillar in the Sijiazhuang Coal Mine, China. Rock Mechanics and Rock Engineering, 52, $1231-1245$.

Yao, Q., Li, X., Sun, B., Ju, M., Chen, T., Zhou, J., Liang, S. \& Qu, Q. 2017. Numerical investigation of the effects of coal seam dip angle on coal wall stability. International Journal of Rock Mechanics and Mining Sciences, 100, 298 - 309.

Yu, B., Zhao, J., Kuang, T. \& Meng, X. (2015). In situ investigations into overburden failures of a super - thick coal seam for longwall top coal caving. International Journal of Rock Mechanics and Mining Sciences, 78, 155 - 162.

Yu, B., Zhao, J. \& Xiao, H. (2017). Case study on overburden fracturing during longwall top coal caving using microseismic monitoring. Rock Mechanics and Rock Engineering, 50, 507 $-511$.

Zhang, C., Mitra, R., Oh, J., Canbulat, I. \& Hebblewhite, B. (2017). Numerical analysis on mining - induced fracture development around river valleys. International Journal of Mining, Reclamation and Environment, 32, 463 $-485$.

Zhang, X., Gong, P., Wang, K., Li, J. \& Jiang, Y. (2019). Characteristic and Mechanism of Roof Fracture Ahead of the Face in an LTCC Panel When Passing an Abandoned Roadway: A Case Study from the Shenghua Coal Mine, China. Rock Mechanics and Rock Engineering, 52, 2775 - 2788.

Zhang, Y. \& Wong, L. N. Y. (2018). A review of numerical techniques approaching microstructures of crystalline rocks. Computers and Geosciences, 115, 167 - 187.

Zhu, G. L., Sousa, R. L., He, M. C., Zhou, P. \& Yang, J. (2020). Stability Analysis of a Non - pillar Mining Approach Using a Combination of Discrete Fracture Network and Discrete Element Method Modeling. Rock Mechanics and Rock Engineering, 53, 269 - 289. 